\title{
Factors Predicting Lower Leg Chronic Exertional Compartment Syndrome in a Large Population
}

Citation for published version (APA):

de Bruijn, J. A., van Zantvoort, A. P. M., van Klaveren, D., Winkes, M. B., van der Cruijsen-Raaijmakers, M., Hoogeveen, A. R., Teijink, J. A. W., \& Scheltinga, M. R. (2018). Factors Predicting Lower Leg Chronic Exertional Compartment Syndrome in a Large Population. International Journal of Sports Medicine, 39(1), 58-66. https://doi.org/10.1055/s-0043-119225

Document status and date:

Published: 01/01/2018

DOI:

10.1055/s-0043-119225

Document Version:

Publisher's PDF, also known as Version of record

Document license:

Taverne

Please check the document version of this publication:

- A submitted manuscript is the version of the article upon submission and before peer-review. There can be important differences between the submitted version and the official published version of record.

People interested in the research are advised to contact the author for the final version of the publication, or visit the DOI to the publisher's website.

- The final author version and the galley proof are versions of the publication after peer review.

- The final published version features the final layout of the paper including the volume, issue and page numbers.

Link to publication

\footnotetext{
General rights rights.

- You may freely distribute the URL identifying the publication in the public portal. please follow below link for the End User Agreement:

www.umlib.nl/taverne-license

Take down policy

If you believe that this document breaches copyright please contact us at:

repository@maastrichtuniversity.nl

providing details and we will investigate your claim.
}

Copyright and moral rights for the publications made accessible in the public portal are retained by the authors and/or other copyright owners and it is a condition of accessing publications that users recognise and abide by the legal requirements associated with these

- Users may download and print one copy of any publication from the public portal for the purpose of private study or research.

- You may not further distribute the material or use it for any profit-making activity or commercial gain

If the publication is distributed under the terms of Article $25 \mathrm{fa}$ of the Dutch Copyright Act, indicated by the "Taverne" license above, 


\title{
Factors Predicting Lower Leg Chronic Exertional Compartment Syndrome in a Large Population
}

\author{
Authors \\ Johan A. de Bruijn 1, *, Aniek P. M. van Zantvoort ${ }^{1, *}$, David van Klaveren², Michiel B. Winkes',

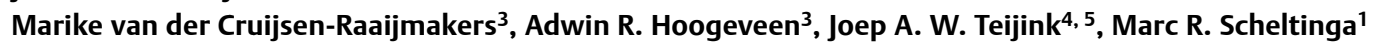

\section{Affiliations}

1 Máxima Medical Center, Surgery, Veldhoven, the Netherlands

2 Erasmus MC, Public health, Rotterdam, the Netherlands

3 Máxima Medical Center, Sports Medicine, Veldhoven, the Netherlands

4 Catharina Hospital, Surgery, Eindhoven, the Netherlands

5 Maastricht University, CAPHRI research school, department of epidemiology, Maastricht, the Netherlands

Key words

CECS, clinical history, physical examination, predictive model, diagnosis, intracompartmental pressure measurements

Accepted after revision 24.08.2017

Bibliography

DOI https://doi.org/10.1055/s-0043-119225

Published online: 10.11.2017

Int J Sports Med 2018; 39: 58-66

(c) Georg Thieme Verlag KG Stuttgart · New York

ISSN 0172-4622

\section{Correspondence}

Mr. Johan de Bruijn, MSc, MD

Máxima Medical center, Surgery

de Run 4600

$5500 \mathrm{MB}$, Veldhoven

Netherlands

Tel.: + 31408888550, Fax: + 31408888550

j.debruijn@mmc.nl

\begin{abstract}
Knowledge about lower leg chronic exertional compartment syndrome (CECS) is largely obtained from highly selected populations. Patient characteristics may therefore not be appropriate for the general population. Our purpose was to describe a heterogeneous population of individuals suspected of lower leg CECS and to identify predictors of CECS. Charts of individuals who were analyzed for exercise-induced lower leg pain in a referral center between 2001 and 2013 were retrospectively studied. Patients were included if history and physical examination were suggestive of CECS and if they had undergone a dynamic intracompartmental pressure measurement. Six hundred ninety-eight of 1411 individuals were diagnosed with CECS in one or more of three lower leg muscle compartments (anterior tibial, deep flexor, lateral). Prevalence of CECS peaked around the age of 20-25 years and decreased thereafter, although a plateau around 50 years was found. Age, gender, bilateral symptoms, previous lower leg pathology, sports (running and skating) and tender muscle compartments were identified as independent predictors of lower leg CECS. The proposed predictive model has moderate discriminative ability (AUC 0.66) and good calibration over the complete range of predicted probabilities. The predictive model, displayed as a nomogram, may aid in selecting individuals requiring an invasive dynamic intracompartmental muscle pressure measurement.
\end{abstract}

\section{Introduction}

Chronic exertional compartment syndrome (CECS) may cause exercise-induced extremity pain in young individuals [20, 26, 29]. CECS is most commonly found in the anterior (ant-CECS), deep flexor (dp-flex-CECS), or lateral (lat-CECS) compartment of the lower leg. [3, 5, 33]. The etiology is a subject of ongoing discussion, but a pathologically elevated muscle compartment pressure is a key factor in the pathogenesis $[1,27]$. The diagnosis is based on a sugges-

*Both authors contributed equally tive clinical history and is supported by elevated intracompartmental pressure. The latter is mostly determined with a dynamic (rather than static) intracompartmental pressure (ICP) measurement [19].

The stereotypical lower leg CECS patient is a young individual who reports a progressively painful and tense muscle compartment during and after exercise [3, 9, 26]. Cramps, muscle weakness and altered skin sensation are also experienced [14]. Symptoms usually subside within half an hour of rest [34]. The current knowledge on CECS is largely based on small or highly selected cohorts such as athletes or military service members and may therefore be biased $[6,15]$. 
The department of Sports Medicine of Máxima Medical Center serves as a referral center for a variety of exercise-induced pain syndromes, exposing it to a large number of individuals who may have CECS $[25,30]$. This population is highly diverse with patients of all ages and levels of sports. The goal of the present study was to describe this heterogeneous population of individuals suspected of CECS who were referred for a dynamic ICP measurement. Furthermore, we aimed to identify predictors for lower leg CECS.

\section{Methods}

\section{Patient selection}

All patients evaluated for lower leg CECS in our department of sports medicine between January 2001 and December 2013 were eligible for this retrospective cohort study. Patients were previously evaluated by a range of clinicians, both from within and from outside of our hospital. As a diagnosis was unclear by then, they were referred to our center for additional analysis. Patients were included for the present study if history and physical examination were suggestive of CECS and if they had undergone a dynamic ICP. A history was considered 'suggestive' if one or more lower leg compartments were reportedly painful or felt tense during training or thereafter. Patients who did not receive an ICP measurement were excluded, as were patients with recurrent CECS or with a CECS of the lower arms or upper legs. The local medical ethical committee judged that the rules laid down in the Medical Research Involving Human Subjects Act (WMO) did not apply to the study protocol. All procedures performed in this study are in accordance with the ethical standards of our institutional research committee, the ethical standards in sports and exercise science research and with the 1964 Declaration of Helsinki and its later amendments [11].

\section{Consultation and ICP measurements}

At presentation, one of two highly experienced sport physicians reviewed the patient's history. Comorbidities such as intermittent claudication, earlier lower leg surgery, venous insufficiency or neurological deficits were tabulated. Significant previous traumatic events including fractures, extensive soft tissue damage, tendon rupture or major vessel damage were also documented. A physical examination was conducted on all individuals. Signs of arterial or venous insufficiency were identified and distal arterial pulses were palpated. Muscle compartments were tested for tenderness and, when indicated, a neurological examination or pedal pulse test was performed. If history and physical examination were suggestive of CECS, ICP measurements of the anterior tibial muscle compartment, the deep posterior compartment, the lateral compartment, or a combination thereof were performed. The choice and number of compartments that were measured were not standardized but dictated by location of symptoms and findings during physical examination. If a patient reported bilateral pain, an ICP measurement was performed in just one leg. Patients with bilateral symptoms and elevated muscle compartment pressure in one leg were considered as having a bilateral CECS. By doing so, the number of invasive ICP measurements was limited, thus minimizing the risk of potential complications such as pain, bleeding, and nerve damage. Details of the slit-catheter technique were described earlier [4,32].
Patients were diagnosed with a CECS if they had a suggestive history and physical examination and at least one ICP value above the three suggested cut-off points ( $\geq 15 \mathrm{~mm} \mathrm{Hg}$ at rest, $\geq 30 \mathrm{~mm}$ $\mathrm{Hg} 1 \mathrm{~min}$ after provocative exercise or $\geq 20 \mathrm{~mm} \mathrm{Hg} 5$ min later) [19]. After the diagnosis, most patients were sent back to their referring physician for treatment. However, some patients underwent surgical treatment in our hospital.

\section{Data collection}

Data were obtained from two electronic sources. Between January 2001 and March 2010, data were extracted from a custom-made Microsoft Access database. We supplemented this database with recordings from paper patient files. Between April 2010 and December 2013, electronic patient files were used. Both databases were combined into one comprehensive data file.

\section{Statistics}

Analyses were performed using SPSS Statistics version 22.0.0.0 (IBM Corp., Armonk, NY, USA) and R version 3.1.3 (R Foundation for Statistical Computing, Vienna, Austria). Data are expressed as mean ( \pm SD) when normally distributed, or as median (with range) when nonparametric. A P $\leq 0.05$ was considered significant. The relation between previous history and unilateral complaints was assessed using chi-square testing. Graphs illustrating the relation between age and risk on CECS were smoothed to improve visual clarity (GraphPad Prism 6). Associations of patient-related variables and the diagnosis CECS were determined using univariable logistic regression. Only variables that were present in $>50 \%$ of the patients were included. Significant variables were included as covariates in a multivariable logistic regression model. Missing values were handled by means of multiple imputation [24].

The strength of the association of each variable with the diagnosis CECS is displayed by its multivariate odds ratio (OR), together with its $95 \%$ confidence interval. Variables without a significant association with the outcome were excluded from the model in a backward approach. The discriminative ability of the final model was assessed with the area under the receiver operating characteristic curve (AUC). In a useless test, such as a coin flip, the AUC is 0.5; a model that discriminates perfectly has an AUC of 1 [10]. The validity of the model was tested with the Hosmer and Lemeshow test and agreement between predicted probabilities and observed frequencies was visualized with a calibration plot. We used bootstrapping to correct the final AUC for optimism. The final model is presented as a nomogram.

\section{Results}

\section{General}

We evaluated 1867 individuals suspected of having CECS between 2001 and 2013 in our facility. Based on an atypical clinical history and/or physical examination, CECS was considered highly unlikely in 153 patients. The remaining 1714 patients underwent an ICP measurement. After exclusion (previous CECS analysis, $n=201$; symptoms in lower arms or upper legs, $n=102$ ), 1411 unique patients suspected of lower leg CECS were included in the present study ( $\triangleright$ Fig. 1). 


\section{Single or multiple ICP measurements}

We performed 1938 ICP measurements in these 1411 patients ( Fig. 2). Measurement of just one compartment occurred in $70 \%$ (983/1411, > Fig. 2, left panel), whereas the remaining $30 \%$ of the individuals underwent ICP measurements of multiple compartments ( $\triangleright$ Fig. 2, right panel). Half of these patients (698/1411, $49 \%$ ) had elevated intracompartmental pressure in at least one compartment. The number of patients with elevated ICP values depended on type of CECS (ant-CECS, $53 \%$ (433/814); dp-CECS, $38 \%$ (344/904); lat-CECS, $35 \%$ (78/220).

\section{Patient characteristics}

- Table 1 depicts characteristics of individuals with CECS $(n=698)$ and without CECS $(n=713)$. Earlier treatment modalities were comparable between the two groups. CECS patients were 8 years younger (median, $25 \mathrm{yr}$, range 12-81) than non-CECS patients (33 yr, range 14-90). The prevalence of CECS decreased with age

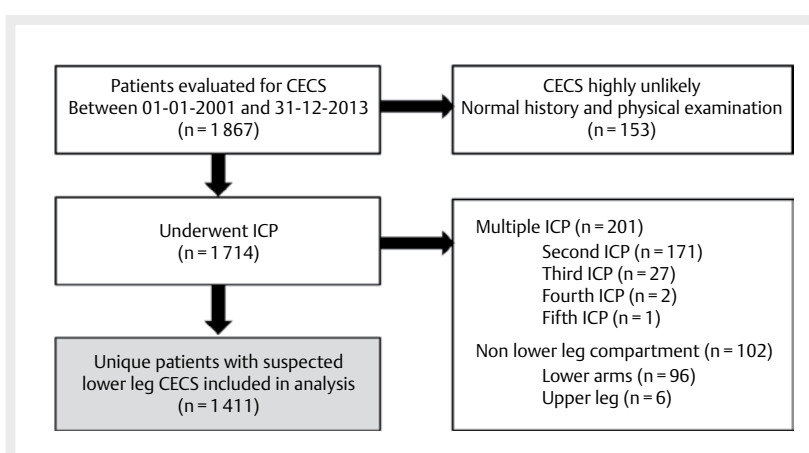

- Fig. 1 Study flow chart of unique patients undergoing dynamic intracompartmental pressure measurement (ICP) for suspected lower leg chronic exertional compartment syndrome (CECS). Multiple ICP: $\geq 1$ previous CECS evaluation including ICPs.
( $\triangleright$ Fig. 3). Patients with unilateral symptoms more often had a history of previous lower leg trauma than patients with bilateral symptoms $(14.4 \%$ vs $3.9 \%, p<0.01)$. Moreover, vascular pathology was more often present in patients with unilateral complaints than in patients with bilateral complaints $(7.2 \%$ vs $3.6 \%, p<0.01)$.

- Table 2 shows patient characteristics of the three subtypes of isolated lower leg CECS. Patients with dp-CECS were 4 and 2 years younger than patients with ant-CECS or lat-CECS, respectively $(p<0.01)$. Approximately three quarters of patients with ant-CECS (72\%) and dp-CECS (78\%) had bilateral symptoms compared to just a little over half of the lat-CECS patients $(53 \%, p=0.04)$. Patients with dp-CECS played soccer more often, whereas patients with ant-CECS were more often engaged in speed skating. Patients not engaged in sports were occasionally found to have ant-CECS but seldom suffered from other types of lower leg CECS ( $>$ Table 2 ).

\section{Predictors of CECS}

Univariable analysis of the whole population of 1411 individuals demonstrated that gender, age, clinical history, bilateral symptoms, type of sports, competitive level of sports and painful palpation during physical examination were associated with the diagnosis CECS ( $>$ Table $\mathbf{3}$ ).

After multiple imputation ( 5 times), we used the predictive variables that were identified with univariable analysis in a multivariable regression model. Age, gender, history of lower leg pathology, bilateral symptoms, type of sports (running and skating) and a painful/tensed compartment during palpation were identified as independent predictors of CECS ( $\triangleright$ Table 4 ). The AUC of the final model was 0.68 . After bootstrapping to correct for optimism to improve the predictive capabilities in a different population, the AUC of the final model was 0.66 . The predicted probabilities were grouped into deciles and the mean probability for each decile was compared with the observed proportions of the diagnosis CECS

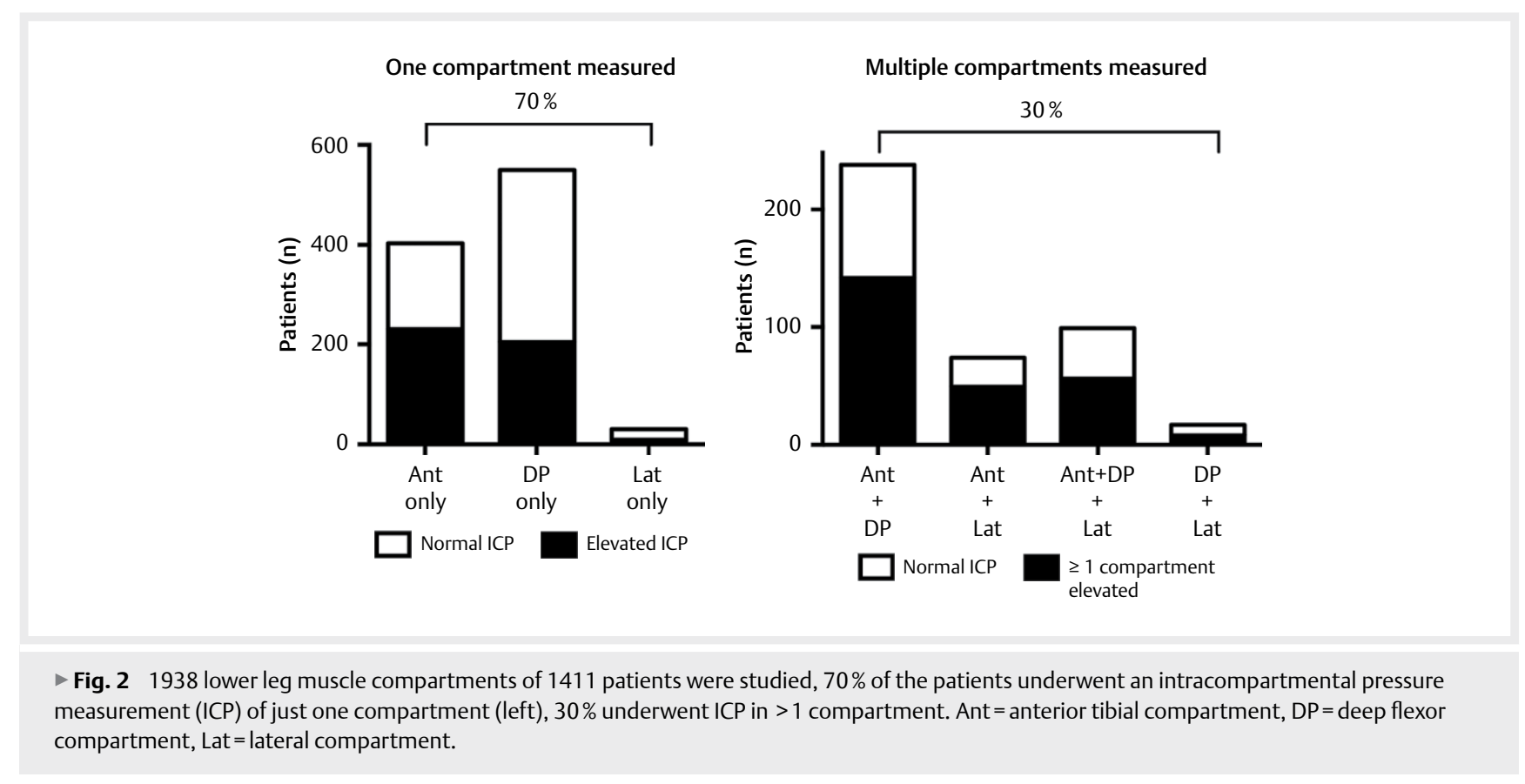


- Table 1 Characteristics of unique patients ( $n=1411)$ who underwent ICP for suspected lower leg CECS.

\begin{tabular}{|c|c|c|c|}
\hline & CECS & non-CECS & Total \\
\hline $\mathrm{n}(\%)$ & $698(50)$ & $713(50)$ & $1411(100)$ \\
\hline \multicolumn{4}{|l|}{ Gender $(n=1411)$} \\
\hline Female n (\%) & $352(50)$ & $426(60)$ & $778(55)$ \\
\hline \multicolumn{4}{|l|}{ Age $(n=1411)$} \\
\hline Median (years) & 25 & 33 & 28 \\
\hline Range (years) & $12-81$ & $14-90$ & $12-90$ \\
\hline \multicolumn{4}{|c|}{ Duration symptoms $(n=1131)$} \\
\hline Median (months) & 18 & 18 & 18 \\
\hline Range (months) & $1-360$ & $1-300$ & $1-360$ \\
\hline \multicolumn{4}{|l|}{ Clinical history } \\
\hline Data available, n (\%) & $595(85)$ & $610(86)$ & $1205(85)$ \\
\hline $\begin{array}{l}\text { No relevant clinical } \\
\text { history, n (\%) }\end{array}$ & $429(72)$ & 362 (59) & $791(66)$ \\
\hline $\begin{array}{l}\text { Relevant clinical } \\
\text { history, n (\%) }\end{array}$ & $166(28)$ & $248(41)$ & $414(34)$ \\
\hline Surgery leg, n (\%) & $64(11)$ & $66(11)$ & $130(11)$ \\
\hline Trauma leg, n (\%) & $33(6)$ & $56(9)$ & $89(7)$ \\
\hline $\begin{array}{l}\text { Peripheral artery } \\
\text { disease, } \mathrm{n}(\%)\end{array}$ & $8(1)$ & $10(2)$ & $18(1)$ \\
\hline $\begin{array}{l}\text { Peripheral venous } \\
\text { disease, } \mathrm{n}(\%)\end{array}$ & $15(3)$ & $25(4)$ & $40(3)$ \\
\hline Other, n (\%) & $46(8)$ & $91(15)$ & $137(11)$ \\
\hline \multicolumn{4}{|l|}{ Previous treatment } \\
\hline Data available, n (\%) & $455(65)$ & 495 (69) & $950(67)$ \\
\hline $\begin{array}{l}\text { Conservative } \\
\text { treatment n (\%) }\end{array}$ & $433(95)$ & $472(95)$ & $905(95)$ \\
\hline Rest, n (\%) & $266(61)$ & $260(56)$ & $526(58)$ \\
\hline Cooling, n (\%) & $47(11)$ & $37(8)$ & $84(9)$ \\
\hline Physiotherapy, n (\%) & $339(78)$ & $379(81)$ & 718 (79) \\
\hline Inlays, n (\%) & $266(60)$ & $270(58)$ & $536(59)$ \\
\hline $\begin{array}{l}\mathrm{CECS}=\text { chronic exertion } \\
\text { mental pressure measu }\end{array}$ & $\begin{array}{l}\text { npartment } \\
\text { nt }\end{array}$ & ome, ICP & zompart- \\
\hline
\end{tabular}

( Fig. 4). Calibration was good for the complete range of predicted probabilities. The final model is displayed as a nomogram ( $\triangleright$ Fig. 5).

\section{Discussion}

Most previous studies on CECS were performed in highly selected populations including elite athletes or military personnel $[2,31]$. The present study describes a heterogeneous patient population with only one selection criterion: all individuals were suspected of having lower leg CECS by their referring physician. Half of these individuals were indeed diagnosed with lower leg CECS as determined by a suspected clinical history and elevated intracompartmental muscle pressures. Age, gender, history of lower leg pathology, bilateral symptoms and a painful/tensed compartment were identified as predictors of CECS.

Previous studies reporting on the relation between gender and CECS are conflicting. Early literature reported a higher male prevalence $[5,19]$, whereas two recent large studies suggested a female

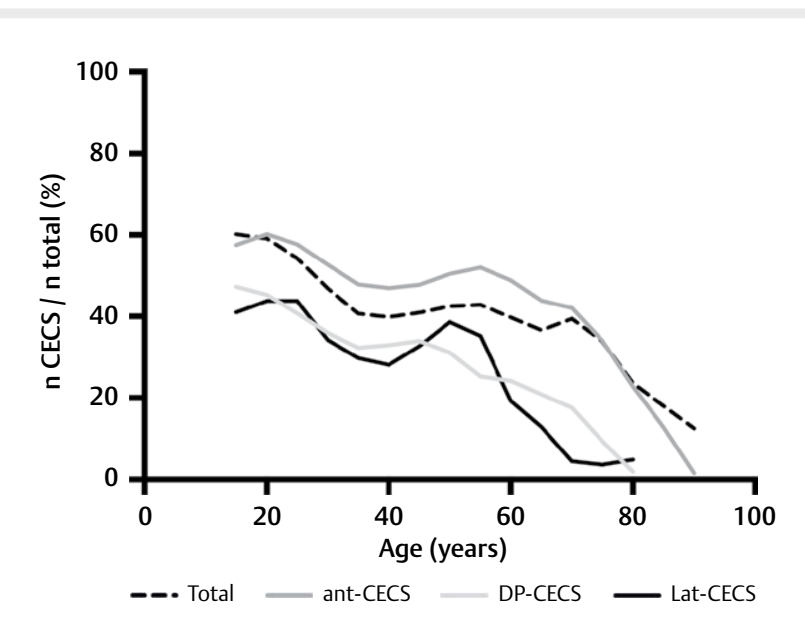

- Fig. 3 Ratio of $\mathrm{n}$ patients diagnosed with CECS divided by total $\mathrm{n}$ of evaluated patients ( $y$-axis) in relation to age ( $x$-axis). AntCECS $=$ isolated anterior tibial compartment CECS, DP-CECS = isolated deep flexor compartment CECS, Lat-CECS = isolated lateral compartment CECS.

predominance $[3,31]$. It is likely that the earlier suggested male predominance is due to selection bias because mostly military personnel and athletes were studied. Moreover, previous cohorts described only patients who were diagnosed with a CECS whereas patients who tested negative for CECS were not studied. The present study included patients with and without CECS. Our analysis demonstrates an equal prevalence of females and males having CECS. However, the initial population of 1411 individuals contained more females (55\%). As a consequence, the portion of females with exercise-induced lower leg symptoms that was diagnosed with CECS was smaller than their male counterparts. Indeed, multivariable analysis confirmed that male gender was associated with a higher likelihood for the diagnosis of CECS.

The available literature suggests that CECS is associated with young age $[5,13,15,27,31]$, although CECS was occasionally also identified in older individuals [7]. The present study confirms that young patients are more prone to develop CECS. Median age at time of diagnosis was 25 years. However, our oldest CECS patient was 81 years. The prevalence of CECS decreases with age. Interestingly, the prevalence stabilized in patients aged around 50 years. Moreover, this plateau is consistently observed in all three types of lower leg CECS. We hypothesize that these older individuals increased their sportive activities because leisure time became more available around this age. Univariable and multivariable analysis confirm that age is an influential factor for the occurrence of CECS.

Lower leg CECS is a predominantly bilateral syndrome $[3,7,16,17,21,28]$. Findings of the present study confirm this bilaterality because $74 \%$ of our total population had CECS in both legs. A novel finding is that bilaterality is CECS type-dependent. $53 \%$ of the isolated lat-CECS patients had a bilateral syndrome compared to $72 \%$ of the ant-CECS and $78 \%$ of the dp-CECS patients. Furthermore, multivariable analysis demonstrated that patients with unilateral complaints were less likely to be diagnosed with CECS than patients with bilateral complaints. Higher preva- 
- Table 2 Characteristics of patients with isolated tibial anterior (Ant), deep flexor (DP), or lateral (Lat) chronic exertional compartment syndrome.

\begin{tabular}{|c|c|c|c|c|c|}
\hline & Ant & DP & Lat & Chi square & p-value \\
\hline $\mathrm{n}(\%)$ & $300(43)$ & $239(34)$ & $19(3)$ & & \\
\hline \multicolumn{6}{|l|}{ Gender } \\
\hline Female n (\%) & $155(52)$ & $115(48)$ & $10(53)$ & 0.72 & 0.70 \\
\hline \multicolumn{6}{|l|}{ Age } \\
\hline Median (years) & 27 & 23 & 25 & $8.9 \#$ & $<0.01^{*}$ \\
\hline Range (years) & $14-81$ & $12-70$ & $17-77$ & & \\
\hline \multicolumn{6}{|l|}{ Duration symptoms } \\
\hline Median (months) & 18 & 21 & 18 & $0.2 \#$ & 0.75 \\
\hline Range (months) & $1-360$ & $3-284$ & $4-120$ & & \\
\hline \multicolumn{6}{|l|}{ Bilaterality } \\
\hline Bilateral symptoms, n (\%) & $214(72)$ & $184(78)$ & $10(53)$ & 6.68 & $0.04^{*}$ \\
\hline Type of sport n(\%) & 273 & 218 & 19 & & \\
\hline No & $26(10)$ & $5(2)$ & $1(5)$ & 10.81 & $<0.01^{*}$ \\
\hline Soccer & $35(13)$ & $69(32)$ & $4(21)$ & 25.75 & $<0.01^{*}$ \\
\hline Running & $54(20)$ & $45(21)$ & $3(16)$ & 0.28 & 0.87 \\
\hline Hiking & $28(10)$ & $12(6)$ & $1(5)$ & 3.91 & 0.14 \\
\hline Hockey & $22(8)$ & $12(6)$ & $1(5)$ & 1.32 & 0.52 \\
\hline Skating & $24(9)$ & $2(1)$ & $1(5)$ & 14.99 & $<0.01^{*}$ \\
\hline Handball & $11(4)$ & $6(3)$ & $0(0)$ & 1.29 & 0.52 \\
\hline Military service & $14(5)$ & $4(2)$ & $0(0)$ & 4.58 & 0.10 \\
\hline Level of sport n(\%) & 189 & 164 & 10 & & \\
\hline No & $26(14)$ & $5(3)$ & $1(10)$ & 13.43 & $<0.01^{*}$ \\
\hline Social & $66(35)$ & $44(27)$ & $3(30)$ & 2.69 & 0.26 \\
\hline Local & $56(30)$ & $90(55)$ & $5(50)$ & 23.34 & $<0.01^{*}$ \\
\hline National & $17(9)$ & $13(8)$ & $1(10)$ & 0.16 & 0.93 \\
\hline International & $5(3)$ & $2(1)$ & $0(0)$ & 1.15 & 0.56 \\
\hline Professional & $18(10)$ & $10(6)$ & $0(0)$ & 2.31 & 0.32 \\
\hline Influence complaints & 173 & 158 & 9 & & \\
\hline Ceased sports & $45(26)$ & $36(23)$ & $1(11)$ & 1.32 & 0.52 \\
\hline Different sport & $2(1)$ & $4(3)$ & $0(0)$ & 1.07 & 0.59 \\
\hline Lower level & $62(36)$ & $67(42)$ & $6(67)$ & 4.29 & 0.12 \\
\hline Same level with complaints & $38(22)$ & $46(29)$ & $1(11)$ & 3.20 & 0.20 \\
\hline
\end{tabular}

lence of previous trauma or vascular pathology in patients with unilateral complaints may explain this finding. Thus, bilateral lower leg symptoms are predictive of CECS, whereas unilateral symptoms may be associated with vascular or traumatic pathology.

Evidence indicates that CECS predominantly occurs in populations engaged in sports activities and military service [2, 3, 31]. Nevertheless, less active individuals or diabetics can also suffer from CECS $[7,8]$. Results of the present study are in line with previous literature. Although not significant, we found a trend that increasing sport intensity appeared to associate with a higher likelihood of the diagnosis of CECS. However, we also found that patients who are not engaged in sports at all may also suffer from CECS, usually of the ant-CECS type. In our population, a wide variety of sports was practiced. Interestingly, only speed skating was associated with an increased likelihood of (ant-)CECS. We suspect that this type of
CECS is related to posture during skating, and this finding may also be applicable for inline skating, rollerblading and other types of skating. In contrast to previous studies, running was associated with a reduced likelihood of CECS. Furthermore, soccer conferred a higher risk on dp-CECS.

The present study has several limitations. Firstly, due to its retrospective nature and the 13-year study period, we were not able to obtain complete datasets in all patients. Therefore, the number of variables that were analyzed was suboptimal and the power of the univariable analysis was reduced. Also, the potential of introducing bias is larger in retrospective studies. Secondly, the current study used ICP measurements (and the Pedowitz criteria) to confirm the diagnosis CECS. Recent literature debates the discriminative value and the role of proposed cut-off points [12, 22, 23]. However, the methods and cutoff points used in the current manuscript 
- Table 3 Univariable associations of potential predictors of CECS $(n=1411)$.

\begin{tabular}{|c|c|c|c|c|c|c|}
\hline \multirow[b]{2}{*}{ Predictors } & & \multirow[b]{2}{*}{$\mathbf{n}$} & \multirow[b]{2}{*}{ OR } & \multicolumn{2}{|c|}{$95 \% \mathrm{Cl}$} & \multirow[b]{2}{*}{ p-value } \\
\hline & & & & LL & UP & \\
\hline \multirow[t]{2}{*}{ Gender } & Female & 778 & ref & ref & ref & ref \\
\hline & Male & 633 & 1.46 & 1.18 & 1.80 & $<0.01^{*}$ \\
\hline Age (years) & & 1411 & 0.98 & 0.97 & 0.99 & $<0.01^{*}$ \\
\hline Duration symptoms (Months) & & 1131 & 1.00 & 1.00 & 1.00 & 0.46 \\
\hline \multirow[t]{2}{*}{ Clinical history } & Not relevant & 789 & ref & ref & ref & ref \\
\hline & Lower leg pathology & 416 & 0.57 & 0.45 & 0.72 & $<0,01^{*}$ \\
\hline \multirow[t]{2}{*}{ Bilaterality } & Bilateral & 941 & ref & ref & ref & ref \\
\hline & Unilateral & 449 & 0.54 & 0.45 & 0.72 & $<0,01^{*}$ \\
\hline \multirow[t]{12}{*}{ Type of sport } & None & 98 & ref & ref & ref & ref \\
\hline & Soccer & 218 & 2.16 & 1.33 & 3.51 & $<0.01^{*}$ \\
\hline & Running & 303 & 0.91 & 0.69 & 1.44 & 0.58 \\
\hline & Hiking & 105 & 1.00 & 0.57 & 1.74 & 0.99 \\
\hline & Hockey & 79 & 1.69 & 0.93 & 3.08 & 0.08 \\
\hline & Fitness & 52 & 1.49 & 2.93 & 0.76 & 0.25 \\
\hline & Cycling & 48 & 0.64 & 0.31 & 1.32 & 0.22 \\
\hline & Skating & 39 & 5.85 & 2.35 & 14.53 & $<0,01^{*}$ \\
\hline & Tennis & 37 & 0.61 & 0.28 & 1.36 & 0.23 \\
\hline & Handball & 36 & 1.79 & 0.83 & 3.88 & 0.14 \\
\hline & Military service & 31 & 3.13 & 1.31 & 7.48 & $0.01^{*}$ \\
\hline & Other & 207 & 1.32 & 0.81 & 2.14 & 0.26 \\
\hline \multirow[t]{6}{*}{ Level of sports } & None & 98 & ref & ref & ref & ref \\
\hline & Social & 328 & 0.98 & 0.62 & 1.54 & 0.92 \\
\hline & Local & 341 & 1.65 & 1.05 & 2.59 & $0.031^{*}$ \\
\hline & National & 56 & 2.30 & 1.17 & 4.53 & $0.016^{*}$ \\
\hline & International & 14 & 4.69 & 1.23 & 17.87 & $0.024^{*}$ \\
\hline & Professional & 56 & 1.98 & 1.01 & 3.86 & $0.046^{*}$ \\
\hline \multirow[t]{4}{*}{ Influence complaints } & Ceased sports & 231 & ref & ref & ref & ref \\
\hline & Different sport & 14 & 0.83 & 0.28 & 2.45 & 0.73 \\
\hline & Lower level & 325 & 1.13 & 0.81 & 1.59 & 0.46 \\
\hline & Same level with complaints & 205 & 1.13 & 0.78 & 1.65 & 0.52 \\
\hline \multirow[t]{2}{*}{ Painful anterior tibia } & No & 648 & ref & ref & ref & ref \\
\hline & Yes & 332 & 0.89 & 0.68 & 1.15 & 0.37 \\
\hline Painful/tensed & No & 483 & ref & ref & ref & ref \\
\hline Compartment & Yes & 687 & 1.88 & 1.49 & 2.39 & $<0,01^{*}$ \\
\hline $\begin{array}{l}\text { Odds ratio }(\mathrm{OR})>1.0 \text { indicates a } \\
\text { ratio }<1.0 \text { indicates a negative } \mathrm{pr} \\
\text { are marked with * }\end{array}$ & $\begin{array}{l}\text { predictive value of the vari } \\
\text { value for } \mathrm{CECS} . \mathrm{Cl}=\text { confid }\end{array}$ & $r$ the & & cor & $\begin{array}{l}\text { te syr } \\
\text { ticall }\end{array}$ & $\begin{array}{l}\text { ). Odds } \\
\text { oredictors }\end{array}$ \\
\hline
\end{tabular}

are widely accepted and the best currently available. Moreover, it must be appreciated that CECS is not solely based on ICP measurements but also requires a suggestive history and physical examination. Thirdly, results of surgery were not available. A favorable outcome after invasive therapy is likely the most valid parameter supporting the diagnosis. Most patients underwent surgery in their referring hospitals and surgical results were, therefore, not available. Lastly, we corrected for optimism with bootstrapping. Although this is an accepted method to test external validity, validation of the current predictive model in a different population is desirable. Also, with an AUC of 0.66 , the predictive model is far from perfect (AUC 1.0). Clinicians should therefore use this model to support decision-making but should not blindly rely on its outcome. The predictive model should not be considered a substitute for dynamic ICP measurements. Strengths of the study are its volume and the heterogeneous population. Furthermore, it is one of few studies to include individuals without CECS, thereby enabling us to provide independent predictors for lower leg CECS.

The differential diagnosis in lower leg pain is extensive. This often results in delay of diagnosis and treatment, with a consequential negative impact on the quality of life, especially in athletes and military personnel $[18,31]$. Furthermore, the CECS diagnosis is 
Table 4 Multivariable associations of predictors of CECS.

\begin{tabular}{|c|c|c|c|c|c|}
\hline \multirow[b]{2}{*}{ Predictors } & & \multirow[b]{2}{*}{ OR } & \multicolumn{2}{|c|}{$95 \% \mathrm{Cl}$} & \multirow[b]{2}{*}{ p-value } \\
\hline & & & LL & UL & \\
\hline \multicolumn{6}{|l|}{ Full set } \\
\hline \multirow[t]{2}{*}{ Gender } & Female & ref & ref & ref & ref \\
\hline & Male & 1.69 & 1.32 & 2.16 & $<0.01^{*}$ \\
\hline Age (years) & & 0.99 & 0.98 & 1.00 & $0.02 *$ \\
\hline \multirow[t]{2}{*}{ Bilaterality } & Unilateral & ref & ref & ref & ref \\
\hline & Bilateral & 1.35 & 1.05 & 1.74 & $0.02 *$ \\
\hline \multirow[t]{2}{*}{ Clinical history } & Not relevant & ref & ref & ref & ref \\
\hline & Lower leg pathology & 0.63 & 0.49 & 0.81 & $<0.01^{*}$ \\
\hline \multirow[t]{12}{*}{ Type of sport } & None & ref & ref & ref & ref \\
\hline & Soccer & 1.19 & 0.57 & 2.48 & 0.65 \\
\hline & Running & 0.57 & 0.35 & 0.93 & $0.03 *$ \\
\hline & Hockey & 1.01 & 0.43 & 2.35 & 0.98 \\
\hline & Handball & 1.15 & 0.45 & 2.95 & 0.76 \\
\hline & Fitness & 1.30 & 0.65 & 2.60 & 0.46 \\
\hline & Hiking & 0.84 & 0.44 & 1.59 & 0.59 \\
\hline & Cycling & 0.54 & 0.25 & 1.15 & 0.11 \\
\hline & Skating & 3.22 & 1.01 & 10.26 & $0.05^{*}$ \\
\hline & Tennis & 0.47 & 0.17 & 1.25 & 0.13 \\
\hline & Military service & 1.55 & 0.36 & 6.58 & 0.55 \\
\hline & Other & 0.84 & 0.43 & 1.65 & 0.61 \\
\hline \multirow[t]{5}{*}{ Level of sports } & Social & ref & ref & ref & ref \\
\hline & Local & 0.95 & 0.61 & 1.47 & 0.80 \\
\hline & National & 1.16 & 0.57 & 2.36 & 0.68 \\
\hline & International & 3.02 & 0.77 & 11.83 & 0.11 \\
\hline & Professional & 0.90 & 0.30 & 2.70 & 0.85 \\
\hline Painful/tensed & No & ref & ref & ref & ref \\
\hline Compartment & Yes & 2.03 & 1.57 & 2.62 & $<0.01^{*}$ \\
\hline \multicolumn{6}{|c|}{ Final Selected model } \\
\hline \multirow[t]{2}{*}{ Gender } & Female & ref & ref & ref & ref \\
\hline & Male & 1.73 & 1.37 & 2.17 & $<0.01$ \\
\hline Age (years) & & 0.98 & 0.98 & 0.99 & $<0.01$ \\
\hline \multirow[t]{2}{*}{ Bilaterality } & Unilateral & ref & ref & ref & ref \\
\hline & Bilateral & 1.39 & 1.09 & 1.78 & 0.01 \\
\hline \multirow[t]{2}{*}{ Clinical history } & Not relevant & ref & ref & ref & ref \\
\hline & Lower leg pathology & 0.64 & 0.50 & 0.83 & 0.01 \\
\hline \multirow[t]{3}{*}{ Type of sport } & Other & ref & ref & ref & ref \\
\hline & Running & 0.61 & 0.46 & 0.80 & $<0.01$ \\
\hline & Skating & 4.03 & 1.70 & 9.59 & $<0.01$ \\
\hline Painful/tensed & No & ref & ref & ref & ref \\
\hline Compartment & Yes & 1.98 & 1.54 & 2.55 & $<0.01$ \\
\hline
\end{tabular}

largely based on a suggestive history and physical examination, but additional invasive testing, such as an ICP measurement, is pivotal $[1,3]$. The literature may suggest characteristics associated with CECS but predictors were hitherto not identified. A simple diagnostic bedside tool for CECS is currently lacking. The present study is the first to provide non-expert clinicians with a method to assist in predicting the likelihood of CECS in a patient with exercise-induced lower leg complaints. By inserting gender, age, bilaterality, previous lower leg pathology, sports (skating and running), and a tensed/painful compartment into the included nomogram, less experienced clinicians can approximate the risk for CECS in a patient with exercise-induced lower leg complaints. This bedside tool may 


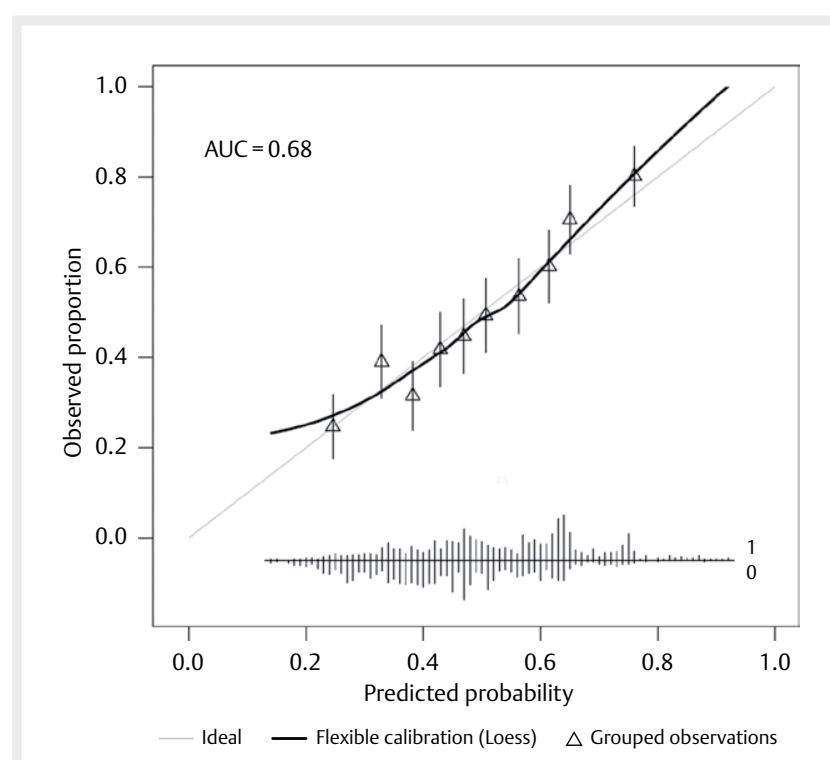

- Fig. 4 Calibration plot of the final model for predicting CECS. The distribution of predicted risks is displayed at the bottom of the graph. Triangles indicate the observed proportion by deciles (y-axis) of predicted risks (x-axis). AUC = area under the receiving operating characteristic curve.

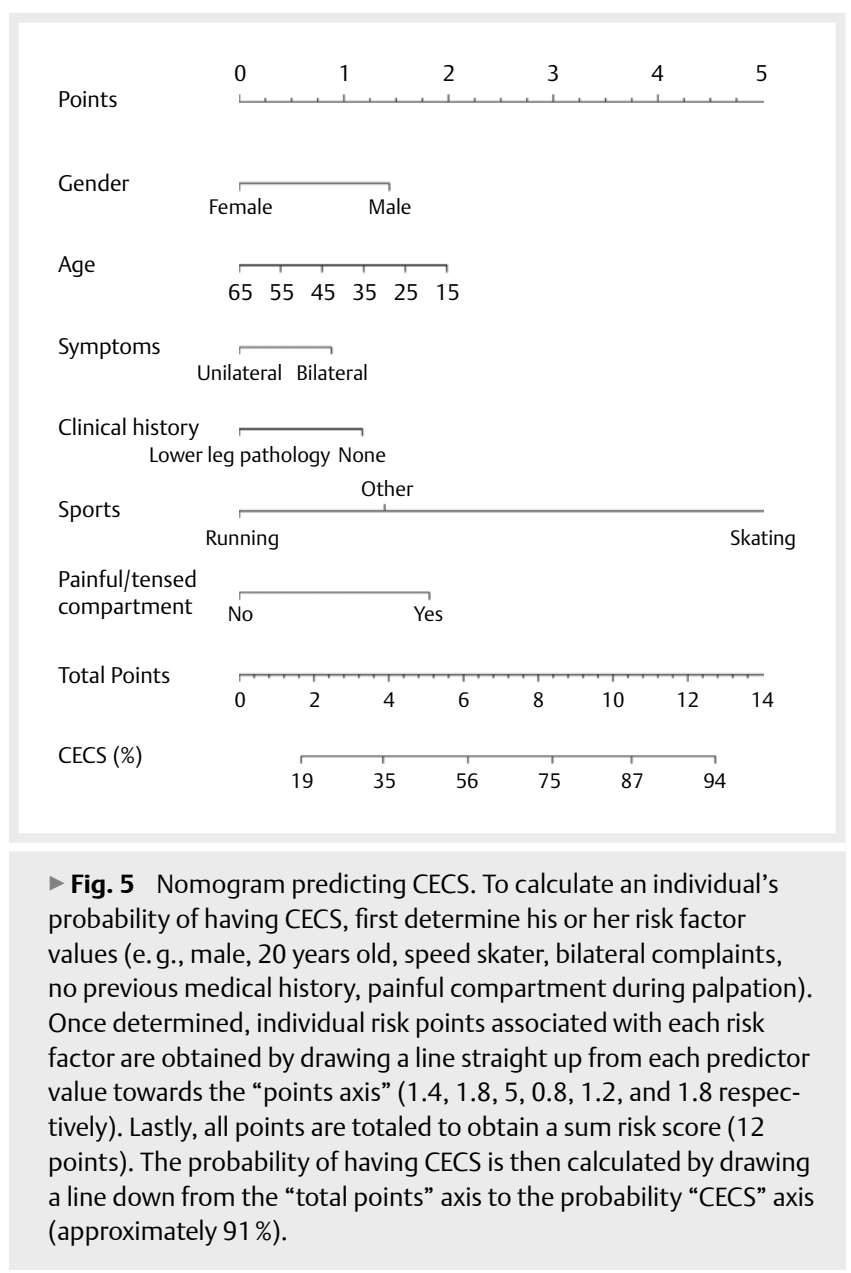

reduce a delay in diagnosis and may aid in selecting individuals that require invasive ICP measurements. In the near future, we plan to validate the current predictive model in a different population.

\section{Conflict of Interest}

The authors have no conflict of interest to declare.

\section{References}

[1] Blackman PG. A review of chronic exertional compartment syndrome in the lower leg. Med Sci Sports Exerc 2000; 32: S4-S10

[2] Clanton TO, Solcher BW. Chronic leg pain in the athlete. Clin Sports Med 1994; 743-759

[3] Davis DE, Raikin S, Garras DN, Vitanzo P, Labrador H, Espandar R. Characteristics of patients with chronic exertional compartment syndrome. Foot Ankle Int 2013; 34: 1349-1354

[4] de Bruijn JA, van Zantvoort APM, Winkes MB, Raaymakers L, van der Cruijsen-Raaijmakers M, Hoogeveen AR, Scheltinga MR. Feasibility and safety of an operative tool for anterior chronic exertional compartment syndrome treatment. Foot Ankle Int 2015; 36: 1475-1482

[5] Detmer DE, Sharpe K, Sufit RL, Girdley FM. Chronic compartment syndrome: diagnosis, management, and outcomes. Am J Sports Med 1985; 13: 162-170

[6] Dunn JC, Waterman BR. Chronic exertional compartment syndrome of the leg in the military. Clin Sports Med 2014; 33: 693-705

[7] Edmundsson D, Toolanen G, Sojka P. Chronic compartment syndrome also affects nonathletic subjects: A prospective study of 63 cases with exercise-induced lower leg pain. Acta Orthop 2007; 78: 136-142

[8] Edmundsson D, Toolanen G. Chronic exertional compartment syndrome in diabetes mellitus. Diabet Med 2011; 28: 81-85

[9] Fronek J, Mubarak S], Hargens AR, Lee YF, Gershuni DH, Garfin SR, Akeson WH. Management of chronic exertional anterior compartment syndrome of the lower extremity. Clin Orthop Relat Res 1987; 217-227

[10] Harrell FE, Lee KL, Mark DB. Multivariable prognostic models: Issues in developing models, evaluating assumptions and adequacy, and measuring and reducing errors. Stat Med 1996; 15: 361-387

[11] Harriss DJ, Atkinson G. Ethical standards in sport and exercise science research: 2016 update. Int J Sports Med 2015; 36: 1121-1124

[12] Hislop M, Batt ME. Chronic exertional compartment syndrome testing: A minimalist approach. Br J Sports Med 2011; 45: 954-955

[13] Howard JL, Mohtadi NG, Wiley JP. Evaluation of outcomes in patients following surgical treatment of chronic exertional compartment syndrome in the leg. Clin J Sport Med 2000; 10: 176-184

[14] Martens MA, Backaert M, Vermaut G, Mulier JC. Chronic leg pain in athletes due to a recurrent compartment syndrome. Am J Sports Med 1984; 12 : 148-151

[15] Micheli LJ, Solomon R, Solomon J, Plasschaert VF, Mitchell R. Surgical treatment for chronic lower-leg compartment syndrome in young female athletes. Am J Sports Med 1999; 27: 197-201

[16] Mouhsine E, Garofalo R, Moretti B, Gremion G, Akiki A. Two minimal incision fasciotomy for chronic exertional compartment syndrome of the lower leg. Knee Surg Sports Traumatol Arthrosc 2006; 14: 193-197

[17] Packer JD, Day MS, Nguyen JT, Hobart SJ, Hannafin JA, Metzl JD. Functional outcomes and patient satisfaction after fasciotomy for chronic exertional compartment syndrome. Am J Sports Med 2013; 41: $430-436$ 
[18] Paik RS, Pepple DA, Pepples D, Hutchinson MR. Chronic exertional compartment syndrome. BM] 2013; 346: f33-f33

[19] Pedowitz RA, Hargens AR, Mubarak SJ, Gershuni DH. Modified criteria for the objective diagnosis of chronic compartment syndrome of the leg. Am J Sports Med 1990; 18: 35-40

[20] Qvarfordt P, Christenson JT, Eklöf B, Ohlin P, Saltin B. Intramuscular pressure, muscle blood flow, and skeletal muscle metabolism in chronic anterior tibial compartment syndrome. Clin Orthop Relat Res 1983; 284-290

[21] Raikin SM, Rapuri VR, Vitanzo P. Bilateral simultaneous fasciotomy for chronic exertional compartment syndrome. Foot Ankle Int 2005; 26: 1007-1011

[22] Roberts A, Franklyn-Miller A. The validity of the diagnostic criteria used in chronic exertional compartment syndrome: A systematic review. Scand J Med Sci Sports 2011; 22: 585-595

[23] Roscoe D, Roberts A], Hulse D. Intramuscular compartment pressure measurement in chronic exertional compartment syndrome: New and improved diagnostic criteria. Am J Sports Med 2014; 43: 392-398

[24] Rubin DB, Schenker N. Multiple imputation in health-care databases: An overview and some applications. Stat Med 1991; 10: 585-598

[25] Schep G, Bender MHM, van de Tempel G, Wijn PFF, de Vries WR, Eikelboom BC. Detection and treatment of claudication due to functional iliac obstruction in top endurance athletes: a prospective study. Lancet 2002; 359: 466-473

[26] Styf J. Diagnosis of exercise-induced pain in the anterior aspect of the lower leg. Am J Sports Med 1988; 16: 165-169
[27] Tucker AK. Chronic exertional compartment syndrome of the leg. Curr Rev Musculoskelet Med 2010; 3: 32-37

[28] Turnipseed WD. Diagnosis and management of chronic compartment syndrome. Surgery 2002; 132: 613-619

[29] Tzortziou V, Maffulli N, Padhiar N. Diagnosis and management of chronic exertional compartment syndrome (CECS) in the United Kingdom. Clin J Sport Med 2006; 16: 209-213

[30] van Zoest W, Hoogeveen A, Scheltinga M, Sala H, van Mourik J, Brink P. Chronic deep posterior compartment syndrome of the leg in athletes: Postoperative results of fasciotomy. Int J Sports Med 2008; 29: 419-423

[31] Waterman BR, Liu J, Newcomb R, Schoenfeld A], Orr JD, Belmont PJ. Risk factors for chronic exertional compartment syndrome in a physically active military population. Am J Sports Med 2013; 41: 2545-2549

[32] Winkes MB, Hoogeveen AR, Houterman S, Giesberts A, Wijn PF, Scheltinga MR. Compartment pressure curves predict surgical outcome in chronic deep posterior compartment syndrome. Am J Sports Med 2012; 40: 1899-1905

[33] Winkes MB, Luiten EJT, van Zoest WJF, Sala HA, Hoogeveen AR, Scheltinga MR. Long-term results of surgical decompression of chronic exertional compartment syndrome of the forearm in motocross racers. Am J Sports Med 2012; 40: 452-458

[34] Winkes MB, van Zantvoort APM, de Bruijn JA, Smeets SJM, van der Cruijsen-Raaijmakers M, Hoogeveen AR, Scheltinga MR. Fasciotomy for deep posterior compartment syndrome in the lower leg: A prospective study. Am J Sports Med 2016; 44: 1309-1316 